\title{
Pollution prevention projects in the Netherlands
}

\author{
T.J.N.M. de Bruijn, F.H.J.M. Coenen and K.R.D. Lulofs \\ Center for Clean Technology and Environmental Policy, University of Twente, 7500 \\ $A E$, Enschede, The Netherlands
}

\begin{abstract}
As part of its waste matter prevention policy, the Dutch government has tried over the past few years to stimulate pollution prevention in firms by means of so-called stimulation and learning projects. To be able to determine the effectiveness of future policies, an extensive evaluation study was performed in 1994 on the pollution prevention projects which had been realized over the past few years. This study* was carried out by the Centre for Clean Technology and Environmental Policy of the University of Twente in Enschede, the Netherlands, commissioned by the Ministry of Housing, Physical Planning and Environment, Waste Matter Board. The aim of the study was to determine the level of success of pollution prevention projects in relation to different circumstances in the implementation of pollution prevention projects in firms. This would provide information which may contribute to the successful setting up of new projects. By 'successful' we mean that they may build on the success formulas of projects completed earlier, consisting of specific project features and other conditions which proved to be of influence. The central research question of the study was: which features make a pollution prevention project efficacious, effective and efficient? This article deals with the structure and results of this study and gives insight into: (1) the results of pollution prevention projects in the Netherlands; and (2) the features of pollution prevention projects which proved to be either more or less successful. Copyright (c) 1996 Elsevier Science Ltd
\end{abstract}

Keywords: pollution prevention; evaluation

\section{Introduction}

As part of its waste matter policy, the central government in the Netherlands has followed a policy which aims to stimulate prevention activities in firms. Over the past years this policy resulted in projects which, while being part of a single main concept, vary as to their structure, methods used, executors and form of financing.

A pollution prevention project is a structure in which various participants collaborate. For example, local authorities, branch organizations, environmental advisers and environmental organizations may act as initiators, financiers, executors and supervisors.

The common aim of the individual projects concerns efforts to deal with the creation of waste and emissions in firms at the source. Thus, pollution prevention projects are set up to point the way, for one or more firms, to pollution prevention and emission prevention.

\footnotetext{
* Main report published in Dutch: T.J.N.M. de Bruijn, F.H.J.M. Coenen, K.R.D. Lulofs en N.E. Marquart, Onderzoek naar de proefprojecten afvalpreventie, 1995
}

Most projects were inspired on the PRISMA method, which is the best-known and most commonly used pollution prevention method in the Netherlands $\dagger$. This method was developed on the basis of a Prevention Manual issued by the American Environmental Protection Agency (Waste Minimization Opportunity Assessment Manual, 1989). The aim was to arrive at a coherent and systematic approach which was suitable within the Dutch context.

The PRISMA method consists of four stages ${ }^{1}$ :

(1). Planning and organization: during the first stage a project team is set up which will coordinate the project within the firm. In addition, the areas of attention are determined after a preliminary study.

(2). Assessment: after collecting data about the firm, its products and its production processes, prevention options are generated for the problem areas which were found.

† PRISMA is the Dutch abbreviation of: PRoject Industriële Successen Met Afvalpreventie (Project Industrial Successes With Pollution Prevention). During this project the method in question was developed further and applied 


\section{T.J.N.M. de Bruijn et al.: Pollution prevention projects in the Netherlands}

(3). Feasibility analysis: the options are judged as to their technical and economic feasibility. Also their environmental effects are determined. On this basis a choice can be made as to the best options.

(4). Implementation: after analyzing their feasibility, the selected prevention options can be introduced. Attention is also given to the measurement and registration of the effects and the incorporation of prevention activities into the firm.

The pollution prevention projects we studied vary as to the exact implementation of this framework. Per firm (sometimes non-profit organization) participating in the project, this concept involves at any rate:

(1). Inspection of the firm as to:

-its substance and material flows;

-the extent of its waste and emission flows (inefficiencies in the substance and material flows); -the causes of these inefficiencies.

(2). Looking for measures aimed at the reduction of waste and emissions on the basis of:

-the collected information about waste and emission flows;

-expcrtise within the firm and within the team of executors.

Insofar as the projects were successful, this prevention-oriented approach meant that less environmental pollution was caused and less waste had to be processed.

The central question posed in our study was: which features make a pollution prevention project achieve its goals, effective and efficient?

In this paragraph we began by discussing the object of the study: pollution prevention projects, in more detail. The next section deals with the basic principles of the study which resulted in the research questions. The evaluation criteria goal achievement, effectiveness and efficiency will be further explained here. In the following section the research questions and the operationalization of the evaluation criteria are discussed. The structure of the study is outlined in the following section, and subsequent sections deal with the results of the pollution prevention projects in tcrms of the extent of goal achievement, effectiveness and efficiency, respectively. An explanation of these reesults is given in the following section, and the article concludes with a number of implications for further policy-making.

\section{Principles of the evaluation study}

Before going into the results of the evaluation study, we first explain the choices that were made regarding the structure of the study. The first choice was to make use of a utilization-focused evaluation approach*.

* In general it is of major importance that the results of a study can be utilized by the principal. Therefore, in a utilization-focused evaluation approach usefulness is placed as a third criterion next to validity and reliability of research results. Usefulness is best defined as consisting of the elements affordability and feasibility of the knowledge pursued. its comprehensibility and the extent to which
During the initial stage of the study the general need for evaluation in consultation between the principal (the Ministry of Housing, Physical Planning and Environment), the supervising committee and the researchers was translated into a suitable study design directed towards useful results. The supervising committee featured policy-makers from the Ministry and executors of pollution prevention projects. Thus both initiators and executors were represented on this committee. They were experts in the area of waste matter and had practical knowledge of the development of pollution prevention projects.

The need for evaluation of the principal and supervising committee appeared to be of a 'closed and structured' typet. This led to the following central research question: which features make a pollution prevention project efficacious, effective and efficient? This research question makes it clear that the need for evaluation appeals to the wish to establish effects followed by assessment and explanation, so as to be able to implement policy adjustments which can make future projects (even) more efficacious, effective and efficient. This calls for a closed and structured study design. A closed structured approach to the evaluation makes the desired assessment and explanation possible and an 'open and unstructured' design does.

Such a closed structured approach usually consists of the following five steps:

(1). Selecting the relevant effects: A selection is made from all imaginable intentional and unintentional, foreseen and unforeseen policy effects. This provides insight into those effects considered relevant.

(2). Researching the extent to which the effects of the pollution prevention projects occurred: The extent to which the effects occurred is determined for each unit of study. This requires a study population and empirical research.

(3). Determining the extent of goal achievement. To be able to evaluate the effects, standards are required; the evaluation criteria. By systematically evaluating the effects, a statement can be made about the extent of goal achievement on those effects deemed relevant. This assessment indicates what the 'score' was on the effects.

(4). Determining the extent of effectiveness: the effects selected in the first step are not by definition

those interested in the study accept this knowledge as relevant and acceptable

$\dagger$ In practice, the need for evaluation can occur in two main forms: (1)Asking questions about what the policy accomplished in the sector of society on which it is focused.

(2)Asking questions about the assessment and explanation of certain facts found in the sector of society.

The first type of evaluation need leads to an 'open and unstructured' policy evaluation. Such an approach takes into account all intentional and unintentional, foreseen and unforeseen effects of policy that occur. The suitable approach is distinguished by the fact that it provides an insight into the wealth of events. However, this makes a clear assessment difficult. At best an explanation of the multiform effects can be achieved in a hermeneutic ('verstehende') manner. Thus, this approach may be better described as an inventory of effects 
policy effects. The concept of policy effects indicates that the impact of the policy will have to be separated from other factors which can basically yield the same effect. This requires a second form of evaluation on the basis of the evaluation criteria. The study design will have to make it likely that the policy's contribution as originator of the effects to be found can be separated from alternative explanations. This second type of evaluation provides an insight into the extent to which the effects that occur are policy effects. This is also described as determining the effectiveness of the policy. It answers the question whether the policy worked.

(5). Explaining the extent of effectiveness: an answer to the question how the policy worked. This explanation answers the question which stimulating and obstructing circumstances explain the results within the firms, providing the user with information which can be used to improve the policy so that it may yield (even) better results.

In the implementation of steps (1) and (3) a so-called 'stakeholders approach' was chosen in this study*. In establishing the evaluation criteria, we distinguish the selection of the effects to be determined, and determination of the standards used to evaluate these effects.

A 'stakeholder' is an actor who has an interest in the outcome of a policy evaluation (interested party). The more the stakeholders become involved in the evaluation and the more the methods and outcomes appeal to them, i.e. the more they recognize their usefulness, the more likely it becomes that the evaluation results are used ${ }^{2.3}$. From a stakeholders approach, the set of evaluation criteria is set up on a relatively broad basis. Thus, different views of what should be the focus of the evaluation are united. It would go too far, however, to think that all stakeholders will eventually consider all evaluation criteria equally important.

If one wishes to improve the policy followed on the basis of the evaluation results, this policy should not just be evaluated, but the policy results should also be explained. Not just the contribution of the policy should

\footnotetext{
* Two orientations can be distinguished regarding the way in which these evaluation criteria are arrived at. A 'top-down approach' focuses on official policy goals as formulated in official policy documents. The 'bottom-up approach' to policy evaluation states that policies are often followed with different or partially different intentions than the official policy objectives that are given. It frequently occurs that ' $A$ ' is written, ' $B$ ' is said, ' $C$ ' is intended and that policy executors and target groups in the policy field translate this as 'basically, the issue is D'. Also, the objectives may have been enhanced, weakened or otherwise altered during the evaluation period. This entails that in such cases evaluation criteria may also be found in other places than just the formal policy programme.

If opinions differ about what is important in the sector of society which is the focus of the policy, a 'top-down' approach will result in different evaluation criteria than a 'bottom-up' approach. If one is prepared to deal with the drawbacks of both these extremes, a well-motivated choice in this dilemma becomes more likely. As such this also constitutes the Achilles' heel of the usefulness of the evaluation results. After all, proposed changes in the policy will not automatically be received enthusiastically if this dilemma is dealt with carelessly
}

be clear but also the restricting and stimulating factors which result in relative differences between units of research. We choose a rationalistic explanatory model where the focus generally is on the comparability between research units and research groups. The actual evaluation results are explained by means of an implicit or - better -explicit causal model of the performed intervention, expected effects and specifying circumstances. This involves a clear structuring of the information one is looking for. The expected effects that were included in the model should be reflected in welldescribed evaluation criteria, the effects being measured with well-defined unequivocal indicators. The specifying circumstances concern those factors or variables which are considered as also having an impact, in addition to the policy, on whether or not positive policy effects arc achieved $\dagger$.

Summarizing, the study may be characterized as a theory-guided rationalistic explanatory evaluation study, in which the evaluation criteria and the explanatory model were implemented on the basis of a stakeholders approach.

\section{Evaluation of the pollution prevention projects}

The central issue of this study, 'which features make a pollution prevention project efficacious, effective and efficient?', was split up, on the basis of the above choices, into the following research questions:

(1). In what way are pollution prevention projects implemented?

(2). Which results are achieved with pollution prevention projects within firms?

(3). Are the objectives of the pollution prevention (projects) achieved?

(4). To what extent are the pollution prevention projects efficient and effective?

(5). Which factors influence the project results within firms?

The first two research questions are descriptive in nature and provide a survey of forms of implementation and results. Questions 3 and 4 evaluate the results in the firms. The fifth research questions has to do with the explanatory part of the study. In answering research questions 2-4 we tried to use evaluation criteria which were as sharply defined as possible, and as operationalized as possible.

\footnotetext{
$\uparrow$ Such a rationalistic approach yields an explanation at the cost of the wealth of information. The alternative is based on the hermeneutic or 'verstehende' explanatory model. The hermeneutic approach is characterized by the fact that the evaluator tries to understand the phenomena. Such an approach is more suitable for descriptive evaluation questions with which one looks for the wealth of events and possibly for an explanation at the aggregated level (i.e. an 'open policy evaluation'), but not the explanation of results at the level of the project and the firm desired, in this study, by the principal (i.e. a 'closed' policy evaluation)
} 


\section{Evaluation criteria and the stakeholders}

From a top-down approach reduction targets can be found in official Dutch waste matter policy. However, these figures at the aggregated level do not tell us how many and which waste matter and emissions should be 'saved' in specific firms which participated in pollution prevention projects from 1990 to 1994 . Also, the contributions of the pollution prevention projects towards achieving the aggregated pollution targets were not the main focus of interest of the Ministry of Housing and Environment, and certainly not that of the other members of the Supervising Committee.

A stakeholders approach involves determining which intended effects of the projects are considered important. In addition to the amount and quality of prevention measures that are provided and implemented, the Ministry also wanted to gain insight into the cost of the achieved results. This provided an extension of the evaluation criteria. Also on the part of the executors of the policies, interpretations of goal achievement were added to the 'top-down' criteria. The executors indicated that at any rate there was also a focus on increased awareness and know-how within firms, sometimes more than on measures to reduce waste and emissions (the 'top-down evaluation criteria'). The executors also indicated that they wished to know whether firms that participated in a pollution prevention project would continue these activities independently after conclusion of the project. A policyrelevant question, since it provides information as to which firms should preferably be the focus of attention. Finally it was suggested by the Supervising Committee that the objectives of firms still often lay in cost economy; reason to add this to the evaluation criteria as well.

In answering the effectiveness question, we deal with the question to what extent the achieved results can be attributed to the policy. In the effectiveness study, use can be made in particular of a comparison with firms that were not involved in the test projects, but are comparable to cases of sample firms from these test projects. This control group enables us to investigate whether the changes that occurred in the test project cases did not occur, or did not occur to the same extent, in firms that did not participate in the test projects. The control firms were matched with the sample firms as to branch and size. This brought to light autonomous developments in the areas of waste and emission prevention. Above that, evaluation questions were asked of officials from the firm about the contribution of the pollution prevention project to the achieved results. The first two columns of Table 1 provide a survey of the indicators. The third and fourth columns of Table 1 indicate how this was done.

Finally, we should clarify how explanatory question 5 was dealt with. Since our aim was a comparison between research units (projects and firms), we once again based ourselves on the rationalistic tradition in policy evaluation. The explanatory theory consists of a model with 62 variables of which it is assumed that they influence the implementation and effects of pollution prevention projects. The model distinguishes three clusters of independent variables which are assumed to influence the dependent variables from the analysis model. These dependent variables concern the criteria for goal achievement included in Table 1.

The variables from the model were developed on the basis of earlier research and the experiences of the stakeholders. For reasons of space, the variables, insofar as they proved relevant, are discussed later.

\section{Structure of the study}

The study design focuses on a structured case-comparative study, using as research methods a contents analysis of project and firm documents and structured interviews of project executors and officials from the participating firms. This triangulation of data and research methods was intended to enhance the reliability of the results. The documents analysis and the interviews were always strictly focused on measuring the values of the evaluation criteria (see Table 1) within the firm in question and determining the values of the explanatory model (see Table 2).

If a case-comparative study is to be used for a causal explanatory model, this will have to be done on the basis of structured and carefully selected case studies $^{4,5}$. By indicating in advance of the study, as described above, which factors are considered relevant, can be influenced or are policy-relevant, the case study can be performed in a sufficiently structured way. This opens the possibility, when performing the evaluation, of linking patterns in conditions as they actually occur to results at the level of the firm when explaining results at the level of all cases taken together.

By a case we mean here a pollution prevention project together with several participating firms. Thus, each case consists of several research units: the pollution prevention project and one or more participating firms.

All in all 24 projects were involved in the study. Within these projects 44 firms were studied. In addition, a control group was set up composed of firms which made 15 one-to-one matchings possible.

One of the main advantages of the case-study design is the fact that a relatively large number of variables can be included in the study. As the research questions show, pollution prevention results in the firms under study were linked to (a) the features of the project in which it participated, (b) the features of the firm, and (c) the features of the firm's environment. The aim of this was to define obstructing and stimulating conditions. The individual units of analysis, i.e. the firms, cannot be seen separately, therefore, from their own environment and the specific context of the test project. Because of this, an evaluation on the basis of a survey held among the firms was not the obvious choice here. After all, an inquiry offers limited possibilities to obtain in-depth knowledge, since it does not take contextual 
Table 1 Use of the indicators in the evaluation criteria of research questions 3 and 4

Indicators

Effectiveness

\begin{tabular}{|c|c|c|c|c|c|}
\hline & & $\begin{array}{c}\text { Goal } \\
\text { achievement }\end{array}$ & Efficiency & $\begin{array}{l}\text { Matching control } \\
\text { firms }\end{array}$ & $\begin{array}{l}\text { Evaluation by } \\
\text { respondents from } \\
\text { firms }\end{array}$ \\
\hline A & Knowledge of waste flows (increase) & $\mathrm{X}$ & & $\mathrm{X}$ & $\mathrm{X}$ \\
\hline B & Knowledge of emissions (increase) & $\mathrm{X}$ & & $\mathrm{x}$ & $\mathrm{X}$ \\
\hline $\mathrm{Cl}$ & Number of proposed prevention options & $\mathrm{X}$ & & $\mathrm{X}$ & $\mathrm{X}$ \\
\hline $\mathrm{C} 2$ & Number of implemented prevention options & $\mathrm{X}$ & & $\mathrm{X}$ & $\mathrm{X}$ \\
\hline D & Financial benefits of prevention options for the firm & $\mathrm{x}$ & & $\mathbf{X}$ & \\
\hline E1 & $\begin{array}{l}\text { Use of differentiation by category of waste and emissions in } \\
\text { development of options (hazardous and non-hazardous) }\end{array}$ & $\mathrm{X}$ & & & \\
\hline E2 & $\begin{array}{l}\text { Percentage of proposed options focused on process and } \\
\text { product changes (compared to total amount including good- } \\
\text { housekeeping) }\end{array}$ & $\mathrm{X}$ & & & \\
\hline E3 & $\begin{array}{l}\text { Extent to which measures within the firm are selected for } \\
\text { implementation on the basis of an environmental criterion }\end{array}$ & $X$ & & & \\
\hline $\mathrm{F} 1$ & $\begin{array}{l}\text { Continuation of prevention study within the firm after } \\
\text { conclusion of the project }\end{array}$ & $X$ & & & \\
\hline $\mathrm{F} 2$ & $\begin{array}{l}\text { Continuation of generation of options within the firm after } \\
\text { conclusion of the project }\end{array}$ & $X$ & & & $\mathrm{X}$ \\
\hline F3 & Presence of organizational elements desirable for prevention & & & & $\mathrm{X}$ \\
\hline F4 & Presence of waste and emission registration system & & & & $\mathbf{X}$ \\
\hline G1 & Project price per participating firm & & $\mathrm{X}$ & & \\
\hline G2 & Project price per developed prevention option & & $\mathrm{X}$ & & \\
\hline G3 & Project price per implemented prevention option & & $\mathrm{X}$ & & \\
\hline
\end{tabular}

Table 2 Model to explain the project results (viz. research question 5)

\section{Project features:}

\begin{tabular}{l} 
(variables $\left.X_{1}-X_{n}\right) \longrightarrow$ Results of pollution prevention \\
Firm features: \\
(variables $\left.X_{n+1}-X_{m}\right) \longrightarrow$ (indicators A-G3) \\
$\begin{array}{l}\text { Features of the firm's environment: } \\
\left.\text { (variables } X_{m+1}-X_{\mathrm{p}}\right) \longrightarrow\end{array}$ \\
\hline
\end{tabular}

influences into account. A case-study design is the ideal way to study the results of pollution prevention in firms in the context where events occur and the intended results are realized, or not achieved.

This design involved a trade-off between available research instruments, the number of cases to be studied and the number of variables of the explanatory model. In view of the limited means at our disposal, it was impossible to let all projects participate in the intended in-depth, structured case-comparative study.

In the second half of this article we present the results of our study.

\section{Goal achievement}

Determining the extent to which the intended results of the test projects have been achieved answers the question about goal achievement. Therefore, in this paragraph we give the situation on indicators $A$ through $F$ as it was found within the firms. Here a three-step approach is used. First we look at knowledge and insights on waste and emissions (indicators $A$ and $B$ ). Next, we look at the options and measures taken (indicators $\mathrm{C}-\mathrm{E}$ ). We conclude with a description of the incorporation of pollution prevention activities in the firms (indicator F).
Assessing the extent of goal achievement is not easy. After all, no upper limit can be given for goal achievement. In other words, no maximum standard is available. The more knowledge, the more measures and the more incorporation, the better. To be able nevertheless to assess the extent of goal achievement, we will at some points compare the effects with the average situation found in the control firms as a standard. The question to what extent the situation that was found can be attributed to the implementation of the pollution prevention projects (the effectiveness question) is not dealt with here.

\section{Knowledge and insight}

A Knowledge of waste flows. The first indicator is the knowledge and level of insight the respondents have, according to their own statements, into the size, origin and environmental harmfulness of three categories of waste flows, i.e. hazardous, common and recyclable waste substances: This indicator was scored on eight five-point scales. Next these scales were added. This results in a minimum value of 8 and a maximum value of 40 (see Table 3). Because no preliminary measurements took place, it is not possible to find a

Table 3 Knowledge of waste flows and emissions (scores of control firms in parentheses)

\begin{tabular}{lcc}
\hline $\begin{array}{l}\text { Effect } \\
\text { Indictor }\end{array}$ & Average level & Range of scores \\
\hline $\begin{array}{l}\text { A. Knowledge of } \\
\text { waste flows } \\
\begin{array}{l}\text { B. Knowledge of } \\
\text { emissions }\end{array}\end{array}$ & $28.9(31.3)$ & $17-40(12-38)$ \\
\hline
\end{tabular}




\section{T.J.N.M. de Bruijn et al.: Pollution prevention projects in the Netherlands}

change in the average level in the sample firms. The only way to discover a change is with repect to another group of firms.

On average the firms scored 28.9. Surprisingly enough, the average score of the control firms is 31.3. In looking at this conclusion we should realize that the indicator used is a subjective one, in the sense that it is not the actual knowledge of the respondents that is measured, but the level of knowledge that the respondents themselves think they possess. It is certainly important here that the main conclusion of the respondents in the sample firms is that the knowledge they possess is largely a result of their participation in the project. An obvious conclusion here is that they gained a realistic view of their own knowledge only in the course of the project. To what extent the assumption is warranted that this means that the respondents in the control firms overestimate their knowledge was not studied further.

$B$ Knowledge of emissions. The second indicator is the level of insight the respondents had, according to their own statements, into the size, origin and environmental harmfulness of emissions into air and water which originate within the firm. The level of insight was scored on three five-point scales, which were subsequently added. Here the minimum value was 3, and the maximum value 15 (see Table 3). On average the sample firms scored 9.7. The average score of the control firms was 10.4. Regarding this comparison we can note the same as for indicator $A$.

\section{Prevention measures}

The numbers and features of prevention methods are given in Table 4.

C1/C2 Numbers of generated and implemented pollution prevention options. Here the first indicator is the number of generated prevention options. The study shows that an average of 23 options was proposed to the sample firms. Out of the options, seven measures

Table 4 Numbers and features of prevention measures (scores of control firms in parentheses)

\begin{tabular}{lll}
\hline $\begin{array}{l}\text { Effect } \\
\text { Indicator }\end{array}$ & Average score & $\begin{array}{l}\text { (Minimum score- } \\
\text { maximum score) }\end{array}$ \\
\hline $\begin{array}{l}\text { C1 Number of } \\
\text { proposed options }\end{array}$ & $23(3)$ & $1-120(1-7)$ \\
C2 Number of & $7(2)$ & $0-35(1-5)$ \\
implemented options \\
$\begin{array}{l}\text { D Positive financial } \\
\text { benefits }\end{array}$ & $68 \%$ & \\
$\begin{array}{l}\text { E1 Differentiation on } \\
\text { the basis of } \\
\text { hazardous/non- } \\
\text { hazardous waste }\end{array}$ & $50 \%$ & \\
$\begin{array}{l}\text { E2 Percentage of } \\
\text { product and process } \\
\text { changes }\end{array}$ & $50 \%$ & $0-100 \%$ \\
E3 Environment as \\
selection criterion
\end{tabular}

were implemented on average. Compared to the control firms the sample firms had a positive score: far more options were generated than in the control firms. The sample firms also implemented far more of the proposed options than the control firms.

$D$ The financial result. We attempted to find out what the financial benefits were for each option by comparing the costs with the benefits. In the end it proved impossible to use the benefits per option as an indicator for this intended result, because:

- data at the firms about the costs and/or benefits were lacking;

- different criteria are used (payback time, savings on an annual basis, etc.);

- companies are in different stages of the prevention implementation programme;

- data were only available within firms about part of the options.

Therefore, as an indicator we used the respondents' opinion whether the pollution prevention activities resulted in positive, negative or neutral benefits within the firm. We may speak of positive benefits if, generally speaking, the financial benefits exceed the costs of investment. The study shows that $68 \%$ of the firms saw a positive financial result of the prevention efforts. Over $20 \%$ of the respondents felt that the financial result of the prevention project was a negative one. A comparison with the situation in control firms as a standard was not possible.

E1/E2/E3 Fundamentality of the generated and implemented options. The first indicator (E1) of the fundamentality of generated and implemented pollution prevention options is the extent to which the distinction between hazardous and non-hazardous waste was taken into account in developing the options. In other words, are the most hazardous waste flows being dealt with, or are they not given any attention? In half of the sample firms we investigated we found that this distinction was applied. In less than one third of the control firms, this distinction was made as well.

The second indicator (E2) of the fundamentality of generated pollution prevention options is the extent to which the prevention options are focused on product changes and/or technical process changes. The study shows that in the sample firms there was a considerable percentage of product and technical process changes (50\%). This means that not only 'good housekeeping' measures, which are often somewhat less complex, were proposed. Too little information was present in the control firms to give a well-founded opinion on product and process changes.

The third indicator (E3) of the fundamentality of generated and implemented pollution prevention options is the extent to which, in the selection of measures, an environmental criterion was used as the main selection criterion. The respondents were asked whether one main criterion was used in selecting the measures to be implemented. 
In selecting measures, feasibility and business-economic criteria appeared to be the main criteria for selection in the majority of firms $(77 \%)$. The environmental criterion was hardly ever the main criterion (one firm).

\section{Incorporation of pollution prevention}

Table 5 shows features of the incorporation of pollution prevention in the firm's organization.

F1/F2/F3/F4 Incorporation of pollution prevention into the organization. Pollution prevention should preferably not be a one-time activity. Therefore we investigated to what extent prevention activities are continued within the firms and whether a number of organizational elements are present in the firm which could indicate a permanent position for pollution prevention within the organization.

The first indicator $(\mathrm{F} 1)$ of incorporation is whether any waste and emission research is done independently, i.e. without any help from outside the firm. After the conclusion of a pollution prevention project, more than half the firms still perform additional pollution prevention research.

The second indicator (F2) of the incorporation of pollution prevention is the extent to which prevention options are generated independently. Also after conclusion of a pollution prevention project, a considerable percentage of the firms $(70 \%)$ still generate new options.

The third indicator of incorporation (F3) is the presence of a number of organizational elements relevant to pollution prevention. Per firm we investigated to what extent five organizational elements are present. They are: appointing an official who is charged with research and options, formulating and choosing measures and/or generating research and options. We also looked at the incorporation of environment in firm policy-making, such as the influence of environmental considerations on investment and the firm's environment as a (permanent) item on the agenda during consultations. On average, 2.6 elements were present within the firms. The fourth indicator of incorporation (F4) is the presence of a waste and emission registration system based on measurements as much as possible. Such a system appeared to exist within vir-

Table 5 Features of the incorporation of pollution prevention in the firm's organization

\begin{tabular}{lll}
$\begin{array}{l}\text { Effect } \\
\text { Indicator }\end{array}$ & Average level & $\begin{array}{l}\text { (Minimum score- } \\
\text { maximum score) }\end{array}$ \\
\hline $\begin{array}{l}\text { F1 Continuation of } \\
\text { prevention study }\end{array}$ & $54 \%$ & \\
$\begin{array}{l}\text { F2 Continuation of } \\
\text { generation of options }\end{array}$ & $70 \%$ & \\
$\begin{array}{l}\text { F3 Presence of } \\
\text { organizational elements }\end{array}$ & 2.6 & $(0-5)$ \\
$\begin{array}{l}\text { F4 Presence of } \\
\text { registration system }\end{array}$ & $87 \%$ & \\
\hline
\end{tabular}

tually all the firms. Only half the control firms had such a system.

Regarding the sample firms, we may speak of goal achievement to the extent that we see: (1) the generation and implementation of fundamental and less fundamental prevention options; and (2) an inclusion of pollution activities within the firm.

\section{Effectiveness}

Within the firms we investigated, the intended results were achieved to a considerable extent. The question now is whether these results can in fact be attributed to implementations of the pollution prevention projects. This is the effectiveness question. The main difference between sample and control firms, after all, is their participation in pollution prevention projects.

To obtain further insight into the relation between pollution prevention projects and goal achievement, a number of sample firms and control firms were matched as to size and branch. By analyzing the differences between comparable firms, rival explanations could be excluded as much as possible. In addition, the respondents were also asked for their opinion, i.e. to what extent they felt that the results could be attributed to the pollution prevention project.

\section{Comparison of goal achievement between matched pairs}

Also after matching we see no clear differences in the level of insight of the respondents into waste flows and emissions (indicators A and B). A possible explanation for this was given previously.

However, far more options were generated and implemented in the participating firms than in comparable control firms (main indicators C-E). The picture which already emerged during comparison with the control firms as a standard is considerably strengthened when answering the effectiveness question on the basis of matched firms. Only the fundamentality of the options and measures proved difficult to compare for the matched firms, because data on this were available with only three of the control firms.

\section{The opinion of the respondents on the effectiveness}

The second approach that was followed to make effectiveness acceptable concerns the opinion of the respondents about the relation between the prevention project and its results. For a large number of indicators of pollution prevention results, the respondents were asked explicitly to what extent these results were due to the pollution prevention projects.

Here we see, for instance, the above-mentioned positive relation between the knowledge of waste flows and emissions and the pollution prevention projects. According to the respondents, this insight could be attributed to the projects to a large extent. A majority of respondents (75\%) also felt that the prevention project yielded a lot of new information. This would 
indicate that the control firms tend to overestimate themselves.

A large majority of the respondents $(75 \%)$ feels that they owed a large part of the generated options to the prevention project. They felt that without supervision by the advisors they would not have developed the options by themselves.

To obtain a better insight into the question to what extent organizational adjustments in the sample firms are a result of the prevention projects, the respondents were asked to what extent these organizational adjustments took place following the project. The study showed that major part of these organizational changes had already been realized before the pollution prevention project.

Pollution prevention projects yield pollution prevention results at the level of the firm, which exceed the results of firms that did not participate in pollution prevention projects.

Regarding the following indicators that were applied, the sample firms scored higher than the control firms: -the generation and implementation of prevention options;

-the fundamentality of the generated and realized prevention options.

The incorporation of pollution prevention in the organization is greater with the sample firms because: -more pollution prevention options were generated independently;

-a pollution and emission registration system was present more often, which was more often based on measurements.

For two indicators, the sample firms did not score higher than the control firms, i.e. the knowledge of waste flows and industrial emissions according to the respondents.

In conclusion we may state that there are sufficient indications that the greater extent of goal achievement with the participating firms compared to the control firms can be largely attributed to the implementation of pollution prevention projects.

\section{The efficiency of the pollution prevention projects}

In our study we also compared the costs and benefits of the projects. The costs were approached from the point of view of the policy-maker. In other words, we weighed the various subsidy amounts against the benefits. These benefits were not defined by us in terms of the quantity or quality of 'saved' waste or emissions or in terms of waste cost savings and other costs of the firm. Most of the respondents in sample firms did not have sufficient precise information on these points. For this reason the costs were plotted against the number of participants, the number of proposed options and the number of implemented measures. This does not yet provide a standard for efficiency. Therefore, the opinion about the costs was formulated in consultation with the committee that supervised the study.
The efficiency of pollution prevention projects was studied on the basis of three indicators. Results are given in Table 6.

The first thing that strikes us here is the enormous diversity of results. While some projects achieve high results at a minimum cost, the costs of certain other projects soar. The question whether an average amount of approximately Hfl. 43,000 for a firm participating in a pollution prevention project is reasonable, cannot be answered unequivocally. At a daily rate of $\mathrm{Hfl}$. 1,400 , this amounts to more than 30 working days. This was seen as rather high by the majority of the supervising committee.

Also the amounts of several hundreds to several thousands of guilders per prevention option were considered to be rather high. Of course, this opinion also depends on the fundamentality of the options. There are some alarming extremes. In some firms this already applied to the proposed options. In a greater number of investigated firms, the price of a realized option compared to a proposed option rose alarmingly. This is an indication of the suspicion that the average price per proposed option was reduced by unworkable options. Moreover, the large price difference between proposed and realized options can also be partly explained by the time of the study. To determine whether this constitutes an acceptable explanation, we looked at how many prevention options the firms still intend to implement. If these options are also counted as measures, the average price per eventually implemented option amounts to some Hfl. 2,850.

The conclusion may be formulated that the efficiency of most of the investigated projects varies tremendously. Average efficiency was seen as being 'just acceptable'.

\section{Explanation of results}

Finally, we tried to arrive at an explanation of the results in firms. In this study we have already explained the extent of goal achievement at the level of individual projects and firms. Here the focus is on finding links between project-, firm- and the firms environmental characteristics (see Table 2) and prevention results (see columns 'goal achievement' and 'efficiency' in Table 1). These results show which features have an

Table 6 The efficiency of pollution prevention projects ( 1 Dollar $=1.6 \mathrm{Hf}$ )

\begin{tabular}{lcc}
\hline $\begin{array}{l}\text { Effect } \\
\text { Indicator }\end{array}$ & Average price (in Hfl.) $\begin{array}{c}\text { (Minimum price- } \\
\text { maximum price) }\end{array}$ \\
\hline $\begin{array}{l}\text { G1 Price per } \\
\text { participant }\end{array}$ & 43,000 & $7200-300,000$ \\
$\begin{array}{l}\text { G2 Price per proposed } \\
\text { option }\end{array}$ & 1780 & $300-56,000$ \\
$\begin{array}{l}\text { G3 Price per } \\
\text { implemented measure }\end{array}$ & 6430 & $370-?^{a}$ \\
\hline
\end{tabular}

a maximum amount cannot be given, because there are firms that did not implement any of the proposed options. 
obstructing or stimulating effect on achieving the desired results.

The Tables 7-9 summarize the project, firm and environmental features which appear to be related to the pollution prevention results. Here it is indicated each time whether there is a positive or a negative relation to a certain feature. We also indicate whether this relation is a strong one $(--$ or + ) or a weaker one - or + ).

In some cases it is also indicated when no relation was found (o), although this was expected. This is followed by a discussion, following each table, of some striking relations.

Some care should be observed in interpreting Tables 7-9. After all, it is not always clear whether a relation also indicates a causal relation, since we can only speak of a causal relation between two variables if:

-There is sequentiality in time;

- There is a correlation between the variables;

-No other explanation of the relation can be given.

The question whether a certain connection indicates a causal relation is not always a problematic one in our study. Thus it is legitimate to assume, for instance, that the proposed prevention options are the consequence of implementation of the prevention project. Sometimes, however, it is not clear what exactly explains a correlation that was found. We shall return to this in our discussion of Tables 7-9.

Without discussing all the relations individually at this point, a number of striking matters emerge. Table 7 shows, e.g., that group meetings (where the project executors do not visit the firm themselves) scored relatively low compared to individually supervised projects. Individual supervision led to higher goal achievement in terms of numbers of options, fundamentality of options (the percentage of product and technical process changes versus good-housekeeping measures) and their implementation. Individual attention pays off, therefore. Support during the implementation of proposed options (often after conclusion of the actual project) had a positive effect. In other words, if after conclusion of the project the project executor kept in touch more or less regularly, pollution prevention remained an item on the firm's agenda for a longer period of time. This will often lead to an increase in project costs, however. For the policy-maker, who is often also the financier of the project, this means that for him there is no 'free lunch'. Good results require relatively large amounts of money and attention!

Table 7 suggests that here the universities do better than commercial consultancy firms. However, from the study we should not draw the conclusion that a certain category of project executors always performs better by definition, since this also depends on the design of the project (available budget, available time, desired approach and results). Here the average approach chosen by the universities in the projects we studied appeared to yield better results than the approaches of the consultancy firms. However, as we see there is no
Table 7 The relation between project features and results

Project feature

Relation to prevention result

There are project executors who +implementation of fundamental concentrate on project options ${ }^{b}$

management (process guidance) $o$ insight into waste and rather than on the executive work

emissions

0 number of options

- - financial benefits of measures

It is a group project (little individual guidance, mainly plenary course days)

$o$ insight into waste and emission - number of options

- fundamentality of options

- implementation of measures

Level of project costs

Length of time the project is continued in the firm

Support provided to the firm during implementation of the measures

+ fundamentality of options

o number of options

o fundamentality of options

++ developing activities after the project

+ implementation of measures 0 financial benefits of measures

During the project the goal is the incorporation of prevention activities in the firm

The executor of the project is a + fundamental benefits of consultancy firm

measures

- number of options

- - fundamentality of options

The executor of the project is a ++ fundamentality of options university

++ fundamentality of implemented options

o number of options

"This table should be read as follows: the more a project possesses a certain feature, the more strongly the effect will occur. For example: the higher the cost of a project, the greater the chance of fundamental options

${ }^{b}$ The fundamental nature of the options and measures is expressed in the percentage which refers to product and technical process changes. The other options are rather in the nature of 'good housekeeping'

causal relation whatsoever between project executor and results.

Also here we discuss a number of striking relations between a firm's features and the results of pollution prevention projects (Table 8 ). As expected, the size of the firm influenced the results; larger firms have more problems, relatively speaking, so they also have more possibilities for prevention. An explanation of the fact that in large firms more activities are continued also after conclusion of a project, could be found in the more frequent presence of staff departments which defend environmental interests and can see to continuation. Actually it appeared that the participants in (the studied) pollution prevention projects are mainly the somewhat larger firms. The average size of the participating firms was 160 employees. Only $10 \%$ of the firms had less than 25 employees. Small firms proved less accessible or less easy to persuade to participate in a pollution control project.

It is striking that the branch in which the firm is active had little influence. In spite of the fact that various different branches were represented in the study, both the number of options and the fundamental nature of the options hardly varied between the different branches. In other words, we found no indications 
Table 8 The relation between firm features and results

\begin{tabular}{|c|c|}
\hline Firm feature & Relation to prevention result \\
\hline Size of the firm & $\begin{array}{l}++ \text { number of prevention options } \\
+ \text { activities after the project } \\
\text { o fundamentality of the options } \\
\text { o implementation of measures } \\
-- \text { insight into waste and } \\
\text { emissions } \\
-- \text { financial benefits of measures }\end{array}$ \\
\hline $\begin{array}{l}\text { Branch in which the firm } \\
\text { operates }\end{array}$ & $\begin{array}{l}\text { + financial benefits of measures } \\
\text { o number of options } \\
\text { o fundamentality of options }\end{array}$ \\
\hline $\begin{array}{l}\text { Number of hours spent on the } \\
\text { pollution prevention project by } \\
\text { the firm (hours spent internally) }\end{array}$ & $\begin{array}{l}+ \text { implementation of measures } \\
+ \text { insight into waste and } \\
\text { emissions } \\
+ \text { fundamentality of options } \\
\text { o number of options } \\
\text { o financial benefits of measures }\end{array}$ \\
\hline $\begin{array}{l}\text { The extent to which the firm } \\
\text { previously participated in } \\
\text { pollution prevention or } \\
\text { associated projects }\end{array}$ & $\begin{array}{l}+ \text { insight into waste and } \\
\text { emissions } \\
++ \text { fundamentality of options } \\
\text { o financial benefits of measures } \\
\text { - number of options }\end{array}$ \\
\hline $\begin{array}{l}\text { Size of firm's environmental } \\
\text { department }\end{array}$ & $\begin{array}{l}\text { H implementation of measures } \\
+ \text { number of options } \\
\text { o insight into waste and } \\
\text { emissions } \\
\text { o fundamentality of options }\end{array}$ \\
\hline $\begin{array}{l}\text { The extent to which the firm } \\
\text { has a system of environmental } \\
\text { care }\end{array}$ & $\begin{array}{l}+ \text { activities after the project } \\
\text { o implementation of measures } \\
- \text { fundamentality of options }\end{array}$ \\
\hline $\begin{array}{l}\text { The extent to which } \\
\text { environmental incidents } \\
\text { occurred within the firm }\end{array}$ & -- financial benefits of measures \\
\hline $\begin{array}{l}\text { Insight of the firm into the } \\
\text { waste tariffs imposed on it }\end{array}$ & $\begin{array}{l}+ \text { insight into waste and } \\
\text { emissions } \\
+ \text { number of options }\end{array}$ \\
\hline Economic returns & $\begin{array}{l}++ \text { activities after the project } \\
+ \text { financial benefits of measures }\end{array}$ \\
\hline
\end{tabular}

that pollution prevention is more difficult in some branches than in others.

It is also striking that participation in related projects does not mean that good results can no longer be achieved. It is true that in this case somewhat less options are proposed (the most obvious measures have probably already been taken), but they are more fundamental in nature. The firm can build on previous experience and thus devote more time to the 'real' problems and to finding more fundamental solutions.

It also makes sense to note that aiming at a greater time investment on the part of the firm itself eventually pays off during the actual implementation of the proposed options. A project design in which all the executive work is performed by external parties is therefore not to be recommended on the basis of our research results. Table 8 also shows the importance of a person, or environmental department, who keeps pollution prevention on the firm's agenda.

The mainly negative relation between (the threat of) government regulation on the one hand (which is evidenced by, e.g., the presence of specific waste regulations in the environmental permit) and the results on the other hand, is striking (see Table 9). We do not know the exact explanation for this. One possible explanation is that more regulation leads to a more expectant attitude on the part of the firm to avoid the risk of 'wrong' investments. The explanation would then be that these firms participate in pollution prevention projects to prepare for future regulations. They wait for the actual implementation of these measures until the moment when it is clear exactly which rules will be imposed.

Furthermore, it is remarkable that a negative selfimage of the firms concerning the environmental functioning of their branch greatly stimulates their activities. In other words, if the entrepreneur is convinced that there may be a problem situation, he takes measures, even if this has negative financial consequences.

\section{The opinion of the firms}

In researching obstructing and stimulating factors, we did not just look at the facts, but also at the opinions held by firms about the pollution prevention projects. The firm's respondent was asked for his opinion on a great many features concerning the design and implementation of these projects. Was he satisfied? Did he see any room for improvement?

A first aspect that was studied was that of recruitment for the project. This is an important stage of a project, since this is the stage at which the firm's interest has to be stimulated. Summarizing the opinions, the form of recruitment appeared to be of little importance. Clear information on what to expect, which logical steps are taken, at what time which activities are expected from the firm, a clear financial picture

Table 9 The relation between features of the firm's environment and results

Feature of the firm's environment

The extent to which waste processing costs influence the economic result

The extent to which the firm experiences difficulties in the processing of waste

The extent to which waste regulations werc imposed on the firm in the environmental permit(s)

The level of environmental pollution in the branch in which the firm operates (according to the firm itself)

The extent to which the branch ++ implementation of measures of the firm has a bad + number of options environmental image (according - financial benefits of measures to the firm itself)
+ insight into waste and emissions

+ fundamentality of options

+ financial henefits of measures

+ activities after the project

- number of options

- implementation of measures

+ implementation of measures

+ activities after the project

o fundamentality of options

++ activities after the project

++ insight into waste and emissions

o fundamentality of options

- - number of options

-- implementation of measures

++ implementation of measures

+ activities after the project

+ number of options 
and insight into the results were perceived as being of great importance during the initial stage. It was not possible to obtain a clear picture of the success of certain recruitment methods and their intensity. In some projects it proved relatively simple to get all the firms that were approached, to participate. In other projects, relatively many firms were approached intensively, but only a few participants were acquired.

A second aspect that was studied was the period of continuation of the project within the firm. A relatively long period was not seen as problematic with the firms, although the respondents did feel that external supervision played an important part in the continuation of pollution prevention, in the sense of having a 'stimulus' and 'pushing things along'.

The most common structuring of activities during the time of the project was the 'prisma-stages differentiation'. It was seen as effective, clear and good. Separate attention for getting acquainted, preparation and project organization development stage is certainly useful. Here the firms warned against an overly theoretical and insufficiently firm-specific implementation.

There were many respondents who felt that the most obvious prevention options were in fact developed. However, nearly $70 \%$ indicated that they encountered problems during implementation of the prevention options. These were problems not just having to with staff or finances, but also of a technical and practical nature. The respondents felt that the workability of the options was not affected by supervision, if any, during the implementation. The previously found relation between support during implementation and the taking of measures points in the opposite direction, however. Regarding this, our conclusions are based on the facts, so they do not correspond to the opinions of the respondents.

The number of hours spent internally was felt to be a problem by one-quarter of the participants. However, this is nearly always seen as a personnel problem rather than a cost problem. It proved difficult to make these sometimes extensive efforts in addition to the 'normal' work.

Quite a few respondents were of the opinion that written and oral reporting in dealing with pollution prevention were essential starting points of contact to mobilize sections of the firm. This would argue in favor of looking for a broad-based forum for presentation and reporting. According to some respondents, this would also facilitate continuation of a project, since many people within the organization would already be informed.

Generally speaking, pollution prevention is not profitable to all participants. It is alarming here that many firms had little insight into the exact financial consequences. The 'Pollution Prevention Pays' slogan should be nuanced, therefore.

One-third of the respondents were disappointed in their expectations in the end; this does mean, of course, that nearly $70 \%$ of participants were generally not disappointed in their expectations.
The interest of respondents within various branches of industry to cooperate in attempts to transfer their experiences to other firms was relatively higher than expected by the research team. Of the firms of the study which had not yet participated in pollution prevention, more than $80 \%$ were interested in the results of other firms. This offers perspectives for a bottomup approach to pollution prevention.

\section{Conclusions and implications for further policy-making}

Answering the research questions

Summarizing, the research questions can be answered as follows.

(1). In what way are pollution prevention projects implemented? This research question is aimed at a description of the way in which pollution prevention projects are set up and implemented. To this end, 24 projects were investigated. The projects are generally aimed at realizing prevention in the participating firms and distributing the achieved results among the other firms. A large part of the projects is carried out by consultancy firms and universities. The projects are generally based on the Prisma method.

(2). Which results are achieved with pollution prevention projects within firms? This research question is aimed at a description of the results that are achieved in firms with the implementation of pollution prevention projects. To this end, 57 firms were investigated. Regarding these firms, we determined to what extent they possessed knowledge and insight into their waste and emission flows, to what extent they took measures to reduce their environmental pollution and to what extent the care for pollution prevention was incorporated into management of the firm. This did show that firms could not indicate concretely what the level of financial costs was and the benefits of the measures taken. The environmental effects also proved difficult to quantify.

In addition, a number of features were described of the firms themselves and their environments. This showed that particularly the somewhat larger firms participate in waste prevention projects. Often these firms were also a bit further advanced with the introduction of environmental care within their firm. Nearly all firms had still been in touch with the licensor over the past two years.

(3). Are the objectives of the pollution prevention (projects) achieved? In the sample firms we can speak of goal achievement to the extent that there is:

- generation and implementation of fundamental and less fundamental prevention options;

-incorporation of pollution prevention within the organization.

The general conclusion with regard to goal 
achievement is that considerable results are achieved in various fields.

(4). To what extent are the pollution prevention projects effective and efficient? The fourth research question is aimed at obtaining insight into the extent to which achieved results may be attributed to the pollution prevention projects and what costs are involved. Two approaches were used here. First, a set of sample firms (participants in pollution prevention projects) was matched with a set of control firms on the basis of the features 'branch' and 'firm size'. This was done in order to exclude rival statements for higher goal achievement in sample firms as much as possible.

The comparison of goal achievement between the pairs of matched firms shows:

-that participating firms generate and implement more prevention options than the control firms;

- that according to the respondents, the insight into waste flows and emissions in the sample firms and in the control firms is at a comparable level.

The second approach that was used to determine to what extent results can be attributed to pollution prevention projects and not to rival factors is the opinion of the respondents. This was explicitly investigated for a number of indicators:

-A large majority of the respondents felt that most options would not have been generated without the project;

-A majority of the respondents felt that the information generated by the project was largely new; -A large part of the respondents saw a positive relation between insight into waste and emission flows and the pollution prevention project.

Furthermore, their opinions show that the sample firms attributed the extent to which the project gave insight into waste flows and emissions largely to the project, in other words, they themselves felt that without the project they would not have obtained this insight.

The conclusion regarding the effectiveness of pollution prevention projects is that, for the greater extent to which the pollution prevention targets were achieved in sample firms as compared to control firms, there are sufficient indications that this can be attributed to implementation of the projects.

In this study the assessment of efficiency was based on three criteria. They are: the price per participating firm, the price per developed prevention option and the price per realized prevention option. The conclusion can be formulated that the efficiency of most of the studied projects is only just acceptable. In our study we did find a few cases, though, where the cost/benefit relation is exceptionally unfavorable.

(5). Which factors influence the project results within firms? In answering the fifth research question, policy effects were analyzed in relation to features of individual projects and individual firms. Basi- cally, this is the question about the explanation of policy effectiveness at the level of individual projects and individual firms. This provides an insight into the stimulating and obstructing circumstances in pollution prevention efforts. It also answers the central problem definition.

Explanatory factors were sought in:

-features of the pollution prevention project;

-features of the firm;

-features of the firm's environment.

Table 7-9 in the previous paragraph summarize the relations that were found.

\section{Recommendations}

Which recommendations can now be made on the basis of the above findings? Obviously, the implementation of pollution prevention projects yields results. The question whether these results could also be achieved by means of other policy instruments was not a subject of our study. Thus, giving a general opinion on whether or not pollution prevention projects should be continued is not the issue here. The research team did formulate a large number of policy recommendations, together with policy-makers and executors in the field of pollution prevention, for setting up future projects with a maximum chance of success. These recommendations reflect a number of themes.

Expertise. Pollution prevention projects are implemented by many different organizations. Although the majority of the respondents were satisfied, generally speaking, with the implementation of the project, the respondents from the firms did point out that one of the main features is branch expertise. This was a problem area in some projects. The executors should have something to offer to the firm. In looking for prevention options they should therefore really be a partner in the discussion. As such, the executors need to understand what is going on in the production process, and on the basis of this knowledge they can make useful suggestions.

Project management. In addition to sufficient branch expertise, the executors of the project need to possess a second quality. For virtually all firms (participation in), a pollution prevention project is not part of the normal management process. This means that it is difficult for them to grasp the design and implementation of such a project. The advantage of taking part in a supervised project for them is the fact that things are put in order. This makes the proper management of a project an important task for the external executors. Much effort should be devoted to communicating with the firm. In spite of the fact that the project executors themselves felt that they werc clear in their communications with the firms, the firms were somewhat more critical about this. A clear phasing of activities in mutual consultation is essential here. Here the firms appreciated the phasing based on the so- 
called prisma method. It is also useful to think about to whom reports should be made. Here the firms preferred a broad-based internal forum to enhance participation.

Recruitment. The recruitment stage of the firms deserves special attention. In some projects this recruitment was difficult: a lot of firms had to be approached to find a limited number of participants. Sometimes recruitment was based on the concept that the firm had a problem (waste and emissions) which could be solved by participation in the pollution prevention project. However, the study among the control firms showed that before a project the firms are not aware of any (potential) problem. It would make more sense, therefore, to emphasize the opportunities offered by participation in a project (better control of goods flows, cost reductions of waste flows) rather than the problems. Being able to point out successful examples from other firms could certainly play a part here. A problem here is the fact that the firms under study are very often unable to indicate concretely which results the project yielded. Thus, we should see to it that the participants in the project quantify the eventual results as clearly as possible, both in terms of money and in terms of environmental gains.

It is also essential that for potential participants a clear picture can be outlined of what participation would involve. The study among the control firms teaches us that they sometimes back down because they are unable to assess the consequences of participation.

Follow-up. The study has shown a clear positive connection between the granting of follow-up care and incorporation into the firm. If support is also offered after the inventorizing stage and the devising of prevention options, there is a greater probability that the concept of prevention will remain part of the firm's management process in the long run as well. This does not have to involve intensive efforts, of course. A monthly phone call or visit to check whether any unexpected problems have arisen can stimulate a firm to remain active.

Finally, it was also recommended to set up an information system. After all, much has happened over the past years within the branches of industry. To prevent any overlaps, insight is needed into what exactly has been developed. The development of pollution prevention methods seems to be complete by now. What is required now are in practice examples of successful prevention options. Also from an international perspective, such an information system may well prove its usefulness. After all, production processes, and therefore environmental problems as well, are often similar in different countries. An exchange of experiences and solutions can serve to prevent having to solve the same problems over and over again.

\section{References}

1 Hoo, S. de et al. "Handleiding voor preventie van afval en emissies (Manual for Prevention of Pollutions and Emissions', SDU, The Hague, 1990

2 Patton, M.Q. 'Utilization-focused Evaluation', 2nd edition, Sage, Beverly Hills, 1986

3 Chen, H.T. and Ross, P.H. 'Evaluating with sense: the theory-driven approach', Evaluation Review, June 1983

4 Boksma, A.F. and Herweijer, M. 'Beleidseffectiviteit en case-studies: een vergelijking van verschillende onderzoeksontwerpen', Beleidswetenschap, jrg. 2, 1988

5 Yin, R.K. 'Case Study Research: Design and Methods', Sage, Beverly Hills, 1984 